\title{
0 FEMININO NO FILME BICHO DE SETE CABEÇAS, DE LAÍS BODANZKY
}

\author{
Maria Fernanda Cavassani* \\ Miriam Cristina Carlos Silva**
}

Resumo: 0 presente artigo faz parte de uma pesquisa maior, que resultou em uma dissertação de mestrado, na qual se buscou compreender as representações do feminino contemporâneo nas obras da cineasta brasileira Laís Bodanzky. Dessa maneira, as investigações foram realizadas partindo das metodologias da análise de narrativa, proposta por Cândida Vilares Gancho (2006), e da análise fílmica, proposta por Francis Vanoye e Anne Goliot-Lété (2012). Neste estudo, o recorte se faz a partir da análise da personagem coadjuvante Meire, do filme Bicho de sete cabeças (2001). Os resultados apontam para uma representação de um feminino marcado pelo patriarcalismo e pelo silenciamento.

Palavras-chave: Narrativa cinematográfica. Feminino. Patriarcalismo. Bicho de sete cabeças. Laís Bodanzky.

\section{INTRODUÇÃO}

O longa-metragem que lança Laís Bodanzky e consolida-a como uma importante cineasta reconhecida nacional e internacionalmente é Bicho de sete cabeças (2001). 0 filme foi inspirado no livro Canto dos malditos, uma autobiografia de Austregésilo Carrano, e apresenta a história de um jovem que é internado em um hospital psiquiátrico.

Sucesso de público e de crítica, o filme levou 450 mil espectadores aos cinemas e, ao ser exibido na Rede Globo, atingiu 37 pontos de audiência (SOBRE..., 2021). Bicho de sete cabeças ganhou 46 prêmios, no Brasil e ao redor do mundo, em diversas categorias, além de ser reconhecido como uma narrativa que aborda os direitos humanos.

\footnotetext{
* Mestrado em Comunicação e Cultura pela Universidade de Sorocaba (Uniso). Licenciatura em Letras pela Universidade Metodista de Piracicaba (Unimep) e em Pedagogia pelo Centro Universitário Sumaré. E-mail: mafecavassani@gmail.com.

** Pós-doutorado em Comunicação Social pela Pontifícia Universidade Católica do Rio Grande do Sul (PUC-RS). Doutorado em Comunicação e Semiótica pela Pontificia Universidade Católica de São Paulo (PUC-SP). Mestrado em Comunicação e Semiótica pela PUC-SP. Professora titular do Mestrado em Comunicação e Cultura da Universidade de Sorocaba, na linha de pesquisa Análise de Processos e Produtos Midiáticos.E-mail: miriam.silva@prof.uniso.br
} 
Sobre a produção do roteiro (1999/2000), que Bodanzky assina com Luiz Bolognesi, ela assume que se emocionou com a história de Canto dos malditos: "Quando li o livro do Carrano, eu ouvi o grito que ele dava no texto e fiquei com vontade de ampliar aquele grito" (QUEM..., 2016).

Ainda sobre a decisão de fazer o filme, em entrevista mais recente, a cineasta descreve: "Fiquei tão tocada com o tema da luta antimanicomial que decidi fazer esse filme. Não era um período fácil, o audiovisual não era reconhecido, ninguém queria se associar àquele drama" (SGANZERLA, 2019).

0 drama apresenta a vida de Neto (Rodrigo Santoro), jovem internado à força em um hospital psiquiátrico após o pai, Wilson (Othon Bastos), encontrar um cigarro de maconha nas coisas do filho. 0 adolescente passa algum tempo no manicômio e vivencia situações que nunca havia imaginado.

A narrativa traz dois debates importantes e complexos: a relação entre entre pais e filhos e a negligência estatal manicomial. Como o foco da pesquisa de mestrado foi a representação do feminino na obra de Laís Bodanzky, o desafio maior foi aguçar o olhar e observar Bicho de sete cabeças a partir das entrelinhas e dos detalhes, uma vez que o protagonista, Neto, e o antagonista, Wilson, são personagens masculinos.

Após assistir ao filme algumas vezes, foi possivel encontrar um fio condutor que possibilitasse a análise do feminino a partir da personagem Meire (Cássia Kiss), mãe do protagonista. Silenciada e subjugada, a personagem nos proporciona reflexões importantes acerca do machismo e do patriarcado, também discutidos neste artigo.

Com o objetivo de investigar como o feminino é representado no filme Bicho de sete cabeças, enquanto percurso metodológico, utilizamos uma proposta de análise hibrida, composta pela análise de narrativa, conforme Cândida Vilares Gancho (2006) e pela análise fílmica, criada por Francis Vanoye e Anne Goliot-Lété (2012).

Para as contribuições teóricas, partimos de três campos conceituais que, para este artigo, são fundamentais: narrativa, feminino e patriarcalismo. Com contribuições acerca de narrativa, apoiamo-nos em Walter Benjamin (1994); para discutir o feminino, Simone de Beauvoir (2009); e, para trazer luz à ideia de patriarcalismo, amparamo-nos em Manoel Castells (2000).

Após a análise, foi possivel chegar a algumas conclusões que apontam para uma representação de um feminino marcado pelo patriarcalismo. Meire é silenciada e oprimida tanto pelo marido quanto pelos filhos.

\section{PROPOSTA METODOLÓGICA}

A proposta de análise de narrativa de Gancho $(2006$, p. 6) permite que se parta da perspectiva de que o cinema possa ser analisado por meio de seu enredo por ser, essencialmente, uma maneira de contar histórias: 
Modernamente, poderíamos citar um sem-número de narrativas: novela de TV, filme de cinema, peça de teatro, notícia de jornal, gibi, desenho animado... Muitas são as possibilidades de narrar, oralmente ou por escrito, em prosa e em verso, usando imagens ou não.

Além disso, o filme tem a estrutura da narrativa composta por cinco elementos essenciais: enredo, personagens, tempo, espaço e narrador $(G A N C H O, 2006)$ e, também, pelo menos um conflito, primordial para o desenrolar da história. Outro ponto da metodologia proposta pela pesquisadora diz respeito à caracterização dos personagens.

Neste trabalho destacamos a importância da construção dos personagens, uma vez que, para debatermos sobre a construção do feminino, a análise se dá, principalmente, na observação das relações que os personagens estabelecem e, também, na observação dos atributos que possuem, podendo ser divididos entre protagonistas, antagonistas e secundários, bem como planos ou redondos (GANCHO, 2006).

Quanto à caracterização de personagens planos ou redondos, a autora explica:

a) Personagens planos: são personagens caracterizados com um número pequeno de atributos, que os identifica facilmente perante o leitor; de um modo geral são personagens pouco complexos (GANCHO, 2006, p. 16).

b) Personagens redondos: são mais complexos que os planos, isto é, apresentam uma variedade maior de características que, por sua vez, podem ser classificadas em:

- físicas: incluem corpo, voz, gestos, roupas;

- psicológicas: referem-se à personalidade e aos estados de espírito;

- sociais: indicam classe social, profissão, atividades sociais;

- ideológicas: referem-se ao modo de pensar do personagem, sua filosofia de vida, suas opções políticas, sua religião;

- morais: implicam em julgamento, isto é, em dizer se o personagem é bom ou mau, se é honesto ou desonesto, se é moral ou imoral, de acordo com um determinado ponto de vista (GANCHO, 2006, p. 18).

Para este estudo, a classificação acima foi fundamental no que diz respeito à análise da personagem Meire. Ainda que este seja um elemento analítico de destaque, os demais não foram deixados de lado. Soma-se, também, à análise de narrativa, a análise filmica, que vai proporcionar um olhar para as questões técnicas, estéticas e sonoras.

A proposta de Vanoye e Goliot-Lété (2012) sistematiza um conjunto de técnicas para observação das narrativas cinematográficas enquanto recorte de um tempo, perspectiva e contexto especificos. Eles sugerem que as investigações sejam realizadas em etapas:

Analisar um filme ou um fragmento é, antes de mais nada, no sentido científico do termo, assim como se analisa, por exemplo, a composição química da água, decompô-lo em seus 
elementos constitutivos. É despedaçar, descosturar, desunir, extrair, separar, destacar e denominar materiais que não se percebem isoladamente "a olho nu", uma vez que o filme é tomado pela totalidade (VANOYE; GOLIOT-LÉTÉ, 2012, p. 14).

0 processo consistiu, então, em fragmentar a narrativa, separando planos (ou atos, como os autores chamam), descrevendo cenas e diálogos. Foram observados, também, aspectos estéticos relevantes à construção da narrativa. Na sequência, buscou-se aplicar, de maneira conjunta, as duas narrativas.

\section{APLICAÇÕES TEÓRICAS}

A narrativa é inerente ao ser humano, particularizando-o em relação a outros seres. Experimentamos e mediamos as experiências vividas, criamos memória e comunicamo-nos por meio daquilo que contamos. Ou seja, temos consciência de nossa existência (e de nosso fim) porque temos a capacidade de pensar sobre esse fato.

Benjamin (1994, p. 198) coloca a figura do narrador como alguém que compartilha experiências, transformando e sendo transformado pelas narrativas, ou seja, cria-se um movimento de troca por meio da narrativa, uma vez que "a experiência que passa de pessoa a pessoa é a fonte a que recorrem todos os narradores".

Para o autor, o narrador deixa marcas na narrativa que, ao passar de pessoa a pessoa, vai transformando-se. Sendo assim, o contar vai se ressignificando e remodelando-se, já que a experiência é sempre individual. 0 filósofo também diferencia informação de narrativa:

Cada manhã recebemos notícias de todo o mundo. E, no entanto, somos pobres em histórias surpreendentes. A razão é que os fatos já nos chegam acompanhados de explicações. Em outras palavras: quase nada do que acontece está a serviço da narrativa, e quase tudo está a serviço da informação. Metade da arte narrativa está em evitar explicações (BENJAMIN, 1994, p. 203).

A narrativa, ao contrário da informação, sobrevive ao poder do tempo, busca se fazer presente e, por ser transmitida de pessoa a pessoa, permanece no mundo, podendo ser constantemente reatualizada. Uma experiência complexa, significativa, envolvente e, no caminho oposto da informação, que é rasa, imediata e perecivel, tem a profundidade necessária para provocar mudanças.

0 cinema, por ser narrativo, pode trazer narrativas aprofundadas com as características que Benjamin (1994) descreve, tornando-se, dessa maneira, um poderoso instrumento de contar e transformar os fenômenos humanos por meio de histórias. A narrativa cinemato- 
gráfica caminha, muitas vezes, lado a lado com as problemáticas de seu tempo e tem condições de fazer as pessoas pensarem sobre determinado assunto e, consequentemente, agirem.

Muitas narrativas cinematográficas têm se debruçado, direta ou indiretamente, sobre as questões de gênero. Ainda que não seja o principal debate em Bicho de sete cabeças, é possivel refletir, a partir da personagem Meire, sobre tais demandas. Aqui, ficamos com a definição de Simone de Beauvoir (2009, p. 11) de que:

Ninguém nasce mulher: torna-se mulher. Nenhum destino biológico, psíquico, econômico define a forma que a fêmea humana assume no seio da sociedade; é o conjunto da civilização que elabora esse produto intermediário entre o macho e o castrado, que qualificam de feminino.

A concepção de que ser mulher é, na verdade, um conceito social e não biológico quebra com ideias preestabelecidas e enraizadas, como, por exemplo, a submissão feminina à figura masculina, uma vez que o homem seria, no senso comum, mais forte do que a mulher. Sobre isso, Beauvoir (2009, p. 65) afirma que
[...] o corpo da mulher é um dos elementos essenciais em sua situação no mundo. Mas o corpo não é suficiente para defini-la como mulher; não há absolutamente verdadeira rea- lidade viva a menos que manifestada pelo indivíduo consciente através de atividades no seio da sociedade.

Beauvoir (2009) esclarece que as ideias de gênero são culturais e sociais, portanto, passíveis de ser questionadas e transformadas. De fato, as mulheres estão reinvindicando espaços antes renegados que, aos poucos, vão sendo conquistados, não sem muita resistência.

A própria Bodanzky já falou sobre como é ser uma mulher que faz cinema em um ambiente dominado por homens: "[...] falta mulher na frente e atrás das câmeras. Isso não vai mudar espontaneamente. Precisamos ter mais roteiristas mulheres, mais mulheres na posição de escolher" (BATISTA, 2020).

0 patriarcado ainda opera em todos os ambientes sociais, públicos e privados, conservadores e progressistas. Ao voltar a observação para o recorte deste texto, a personagem Meire do filme Bicho de sete cabeças, tal percepção fica ainda mais evidente. Surge, então, a necessidade de compreender o conceito de patriarcalismo.

Castells (2000) afirma que todas as sociedades contemporâneas se assentam na estrutura pratiarcal. Desde ambientes institucionais até familiares, existe uma autoridade masculina que dita as regras e organiza a sociedade. 0 patriarcalismo estrutura e condiciona todas as relações e é marcado pela dominação e violência: 
Caracteriza-se pela autoridade, imposta institucionalmente, do homem sobre a mulher e filhos no âmbito familiar. Para que essa autoridade possa ser exercida, é necessário que o patriarcalismo permeie toda a organização da sociedade, da produção e do consumo à política, à legislação e à cultura (CASTELLS, 2000, p. 169).

Estando enraizada no âmbito familiar, essa estrutura opressora afeta todos os membros daquele núcleo, que acabam por reproduzir costumes questionáveis, mas nem sempre questionados. 0 patriarcado opera por meio do medo e, por muito tempo, tem mantido seu poder dessa maneira.

A organização social e familiar centrada na figura masculina só é possível porque existe forte submissão e controle: "[...] não fosse a família patriarcal, o patriarcalismo ficaria exposto como dominação pura e acabaria esmagado pela revolta da 'outra metade do paraíso', historicamente mantida em submissão" (CASTELLS, 2000, p. 169).

Ao analisar a personagem Meire com as contribuições teóricas que embasam este trabaIho, chega-se a percepções e reflexões importantes. Entretanto, antes da análise e das considerações, apresentamos descrição, categorização e cenas que nos ajudaram a compreender o feminino em Bicho de sete cabeças.

\section{DESCRIÇÃO E CATEGORIZAÇÃO DO FILME BICHO DE SETE CABEÇAS}

A metodologia de observação do longa-metragem consistiu em, primeiramente, descrever de uma perspectiva técnica o filme a partir de nosso foco analítico, a personagem Meire, mãe do protagonista. Depois, separamos cinco cenas - que Francis Vanoye e Anne Goliot-Lété (2012) chamam de atos -, que julgamos importantes à compreensão do filme.

Após a etapa mais técnica, categorizamos o filme com base nos cinco elementos narrativos propostos por Gancho (2006). Por último, levantamos questões e trouxemos contribuições interpretativas sobre o que mais nos interessou observar no filme: o feminino.

0 filme tem início com um homem que abre uma folha de papel e uma voz em off narra o que está escrito ali. 0 homem em questão é Wilson, pai do protagonista, Neto. Nas cenas que se seguem, observamos o menino andando de skate e, depois, a cena corta para pessoas sentadas à mesa.

A familia é composta por pai, mãe, uma filha e Neto, o mais jovem. Percebe-se que Wilson é quem decide pela familia, enquanto Meire, em quase todas as cenas segurando um cigarro entre os dedos, apenas serve aos demais e observa o que está acontecendo. Neto sai ao encontro dos amigos. Seu pai, na sequência, vai buscá-lo. 
Quadro 1 Roteiro de atos selecionados de Bicho de sete cabeças

\begin{tabular}{cl}
\hline \multicolumn{1}{c}{ Ato 1} & $\begin{array}{l}\text { Conhecemos Meire, a mãe de Neto, em um momento em que a família toma } \\
\text { café da manhã. O filho sai acompanhado de uma amiga, e a mãe é questionada } \\
\text { pelo pai sobre o porquê de a garota ter dormido na casa da familia. Ao final } \\
\text { da sequência, a câmera foca Meire jogando um cigarro dentro de um copo } \\
\text { de café. }\end{array}$ \\
\hline
\end{tabular}

Fonte: Cavassani (2020, p. 86).

A cena que se segue tem o ponto de vista de Neto. Enquanto o pai fala, ele ouve e vê de maneira turva, a boca do pai treme e a voz ecoa. Percebe-se, então, que o garoto usou alguma substância psicoativa. 0 pai não parece notar e pergunta sobre a namorada do filho. Entre outras coisas, fica evidente que Wilson busca controlar o jovem.

De manhã, Meire vai acordar o garoto. A mãe parece cuidar de Neto e fazer tudo por ele, enquanto o pai o pressiona para trabalhar e estudar. Pai e filho têm outra discussão e Neto sai de casa bastante irritado com a situação e com o conflito com Wilson. Meire vai atrás dele.

Quadro 2 Roteiro de atos selecionados de Bicho de sete cabeças

\begin{tabular}{cl} 
Ato 2 & $\begin{array}{c}\text { Neto e Wilson discutem porque o garoto decide viajar sem o consentimento } \\
\text { do pai. Neto sai apressado de casa e a mãe o chama, na esperança de, talvez, } \\
\text { impedi-lo, mas não adianta e ela volta para dentro da residência. }\end{array}$ \\
\hline
\end{tabular}

Fonte: Cavassani (2020, p. 86).

0 menino viaja com um colega à praia. Os amigos têm uma discussão e Neto pede dinheiro às pessoas na rua para poder retornar. Encontra uma mulher que o leva para casa. Lá, ele conhece os amigos dessa pessoa, que fumam maconha e festejam. 0 jovem acaba passando a noite com a mulher e, na sequência, volta para sua casa.

Vemos o jovem na escola, interagindo com colegas e compartilhando cigarros de maconha. Durante a noite, ele sai para pichar muros na companhia de outros meninos e a polícia os surpreende, prendendo todos eles. Wilson e Meire vão buscar o filho na delegacia. 0 pai está furioso e a mãe, apática a calada, mais uma vez com o cigarro entre os dedos.

Quadro 3 Roteiro de atos selecionados de Bicho de sete cabeças

\begin{tabular}{cl} 
Ato 3 & Wilson e Meire vão buscar Neto na delegacia. 0 filho foi preso por estar \\
Cena 00h 18m 06s & pichando muros pelas ruas. Todos dentro do carro estão desconfortáveis. \\
\hline
\end{tabular}

Fonte: Cavassani $(2020$, p. 86). 
Os conflitos entre pai e filho seguem. Neto chega em casa e Wilson, furioso, mexe na mochila do filho, encontrando um cigarro de maconha. Em vez de decidir com Meire qual atitude tomar, ele procura por sua filha mais velha, que o aconselha a internar o garoto em um hospital psiquiátrico. A mãe é completamente desconsiderada em qualquer decisão e, aparentemente, contra a decisão.

A internação em hospital psiquiátrico de fato acontece. Neto passa por situações degradantes, abusos e humilhações. 0 ambiente é perturbador, e ele sente-se muito mal em estar ali. Após algumas semanas, a família vai visitá-lo e o garoto insiste para que o levem de volta para casa, o que não acontece. Ele ficaria alguns meses internado.

Quadro 4 Roteiro de atos selecionados de Bicho de sete cabeças

\begin{tabular}{cl} 
Ato 4 & $\begin{array}{l}\text { Após duas semanas de internação, a família visita Neto, que toma ciência de } \\
\text { que ficará mais alguns meses internado. } 0 \text { jovem se desespera e implora para }\end{array}$ \\
Cena 00h $41 \mathrm{~m} \mathrm{26s}$ & a mãe que o tire de lá, sem sucesso, pois Wilson está irredutivel. \\
\hline
\end{tabular}

Fonte: Cavassani (2020, p. 86).

Na cena do encontro, nota-se que ele pede ajuda principalmente à mãe, implorando para ir embora. 0 pai e a irmã se mantêm firmes em deixá-lo internado, enquanto Meire parece querer ajudar o filho. Entretanto, ela é desconsiderada a todo momento, apesar de tentar mediar a situação.

Neto continua internado, e os abusos também continuam. Bodanzky consegue trazer muita veracidade à representação daquele ambiente hostil. 0 uso de uma iluminação mais densa traz certo peso dramático às cenas. Closes e planos mais fechados aproximam o espectador das angústias vividas por Neto.

Após meses de violências, prescrição de remédios e terapias humilhantes, o garoto pode retornar à casa. Entretanto, a essa altura, ele não é mais o mesmo e carrega inúmeros traumas e tristezas. Parece estar fora de si, enquanto Wilson e Meire tentam se aproximar dele.

Quadro 5 Roteiro de atos selecionados de Bicho de sete cabeças

\begin{tabular}{cl}
\hline Ato 5 & Neto sai da clínica psiquiátrica muito deprimido. Meire tenta aconselhá-lo \\
a voltar a estudar, mas o garoto se nega. Ela, então, propõe que ele comece a \\
Cena 01h 24m 23s & trabalhar e, depois de relutar, Neto acaba aceitando. \\
\hline
\end{tabular}

Fonte: Cavassani (2020, p. 86). 
Meire busca ajudar Neto da maneira como pode, aconselhando-o, dando-Ihe atenção e carinho. Entretanto, não é suficiente. 0 garoto tem muita dificuldade em se reintegrar socialmente, não consegue estudar ou trabalhar, envolve-se em brigas e acaba sendo internado novamente. Tenta se suicidar.

Neto sai do hospital psiquiátrico e o filme termina com ele e Wilson sentados em uma calçada. 0 pai chora, e o filho tem o olhar triste e vago. A música Bicho de sete cabeças começa a entoar:

\author{
Não dá pé não tem pé nem cabeça \\ Não tem ninguém que mereça \\ Não tem coração que esqueça \\ Não tem jeito mesmo \\ Não tem dó no peito \\ Não tem nem talvez \\ Ter feito o que você me fez \\ Desapareça cresça e desapareça \\ Não tem dó no peito \\ Não tem jeito \\ Não tem coração que esqueça \\ Não tem ninguém que mereça \\ Não tem pé não tem cabeça \\ Não dá pé não é direito \\ Não foi nada, eu não fiz nada disso \\ E você fez um bicho de sete cabeças \\ Bicho de sete cabeças (BICHO..., 1979).
}

Ao terminar o filme com a música que dá nome ao longa, Bodanzky adiciona uma camada interpretativa. A cineasta usa esse elemento sonoro e promove uma convergência significativa entre narrativa e música, uma vez que existe um diálogo evidente.

A cineasta tem um grande cuidado estético e sonoro nessa narrativa cinematográfica. Consegue passar toda a angústia e desespero para o espectador, vindos de uma pessoa que está sendo internada em um hospital psiquiátrico. Contudo, talvez seja na construção dos personagens que a diretora é ainda mais certeira.

Ao observar os personagens de acordo com a metodologia de análise de narrativa (GANCHO, 2006), é possivel chegar a algumas conclusões necessárias para aprofundar os debates acerca do feminino. 0 Quadro 6 ajudará nas construções analíticas que aqui realizamos: 
Quadro 6 Categorização das personagens

\begin{tabular}{lllll}
\hline Enredo & Personagens & Ambiente & Narrador & Feminino \\
\hline $\begin{array}{l}\text { Conflito: } \\
\text { Psicológico }\end{array}$ & $\begin{array}{l}\text { Protagonista: } \\
\text { Neto (herói) }\end{array}$ & $\begin{array}{l}\text { Espaço: } \\
\text { Familiar/Hospitalar }\end{array}$ & $\begin{array}{l}\text { Silencioso e } \\
\text { onisciente }\end{array}$ & $\begin{array}{l}\text { Personagem: } \\
\text { Mãe, Meire } \\
\text { (plana) }\end{array}$ \\
$\begin{array}{l}\text { Temas: } \\
\begin{array}{l}\text { Universais } \\
\text { (adolescência, }\end{array}\end{array}$ & $\begin{array}{l}\text { Wilson e Estado } \\
\text { relações }\end{array}$ & $\begin{array}{l}\text { Tempo: } \\
\text { (vilões) }\end{array}$ & (anos 2000) & \\
$\begin{array}{l}\text { familiares, } \\
\text { negligência }\end{array}$ & Secundário: & & & \\
manicomial) & Mãe, Meire & & & \\
\hline
\end{tabular}

Fonte: Cavassani (2020, p. 87).

Todos os elementos narrativos elencados por Gancho (2006) estão presentes em Bicho de sete cabeças. Existe enredo conflitante que aborda temas universais; espaço e tempo bem delimitados, um narrador que tudo vê, mas é nos personagens e nas relações que estabelecem que o debate, de fato, acontece.

Entre personagens planos e redondos, Bodanzky dirige uma narrativa comovente. Neto e Wilson estão nos papéis de protagonista e antagonista, respectivamente, enquanto Meire está em papel secundário. Os primeiros são redondos, complexos, com nuances e camadas, enquanto Meire é plana, passiva, previsivel.

\section{ANÁLISE E POSSÍVEIS CONSIDERAÇÕES}

São muitas as violências presentes no filme Bicho de sete cabeças, situações essas que constituem a realidade de inúmeras pessoas. É possível que seja por isso que o filme tenha sido tão bem recebido e seja, até agora, depois de duas décadas, uma referência cinematográfica de grande relevância para diferentes áreas do conhecimento.

Talvez, dentro de nossa pesquisa maior, que foi observar a questão do feminino em toda a obra da cineasta Laís Bodanzky, essa narrativa tenha sido a mais desafiadora. A proposta de analisar uma personagem secundária feminina, com poucas falas e muitos silêncios, não foi simples, mas rendeu conclusões interessantes.

Antes de refletir sobre tais conclusões, é preciso analisar Meire com mais atenção. Mulher de meia-idade, casada, mãe de dois filhos e dona de casa, no decorrer da narrativa, ela tem pouco tempo de tela e poucas falas. Suas interações com os demais são superficiais e, ainda que ela tente ser ouvida, não consegue. 
Meire representa grande parte das mulheres que empenham suas vidas para cuidar e servir à família. A pessoa que, por necessidade ou opção, tem a vida dedicada ao ambiente doméstico sofre com a privação de sua individualidade e torna-se, muitas vezes, apenas quem varre, passa, lava e cozinha. Beuavoir (2009, p. 224) reflete sobre a mulher dona de casa:

Poucas tarefas são mais parecidas com a tortura de Sísifo do que o trabalho doméstico, com sua repetição sem fim: a limpeza se torna sujeira, a sujeira é limpeza, uma e outra vez, dia após dia. A dona de casa se desgasta com o passar do tempo: ela não faz nada, apenas perpetua o presente. Comendo, dormindo, limpando - os anos já não se levantam para o céu, eles se espalham adiante, cinzas e idênticos. A batalha contra a poeira e a sujeira nunca é vencida.

Além de não ser, em nenhum momento, reconhecida ou retribuída pelo trabalho não remunerado que faz em casa, Meire ainda sofre com a invisibilidade e o descrédito de todos os integrantes da família. Resta a ela a única atitude autônoma que apresenta: fumar, além de usar remédios para dormir, o que não se constitui em uma ironia quando se percebe que seu filho caçula é condenado a uma série de violências em função do uso da maconha.

0 ato de fumar de Meire parece ser um símbolo de emancipação do marido e dos filhos, um momento em que ela pode fazer o quer. Em quase todas as cenas em que está presente, o cigarro a acompanha e parece tornar-se um objeto-cúmplice, uma fuga da realidade que a aprisiona e oprime. A liberdade de Meire começa e termina no cigarro. Sua atuação é caracterizada pelo silenciamento: em silêncio, submete-se às regras e decisões tomadas pelo marido, ainda que sua tensão demonstre que quase nunca está de acordo com aquilo que foi decidido.

A caracterização de Meire enquanto personagem plana (GANCHO, 2006), invariável, pouco relevante para o desenrolar da narrativa, dá-nos condições de pensá-la, principalmente, no contexto do patriarcalismo, que marca as relações familiares e sociais do nosso tempo.

Wilson, o marido e pai, é a figura central daquele núcleo familiar. Ele decide tudo e busca um controle sobre todos que ali vivem. Wilson é a representação do patriarcalismo porque usa esse poder que the é moralmente conferido pela sociedade para coagir e impor suas crenças e vontades.

É interessante notar a diferença de tratamento que Wilson oferece para Neto e para Meire. Apesar de o garoto não corresponder às expectativas do pai em relação às escolhas de vida, estudos e carreira, Wilson busca interná-lo para que ele "vire homem" e tem esperanças de que o filho possa ser e pensar como ele próprio, o pai. Neto é homem.

Com Meire, a relação estabelecida é diferente. Wilson trata-a como uma pessoa de menor valor, insignificante, que não deve ter suas ideias e ideais considerados e legitimados. A esposa tem como funções a subserviência e a obediência ao marido, e nada mais. Meire é mulher. 
Não existe Meire sem Wilson, mas existe Wilson sem Meire. E tal dependência unilateral da esposa em relação ao marido é injusta com as mulheres, porque coloca-as em posição de inferioridade, gerando, portanto, dificuldades em estabelecer laços de amor e afeto saudáveis, já que uma das partes envolvidas está sempre em desvantagem:

No dia em que for possivel à mulher o amor não em sua fraqueza, mas em sua força, não para escapar de si mesma, mas para se encontrar, não para se abater, mas para se afirmar. Naquele dia o amor se voltará para ela, assim como para o homem, a fonte de vida e não de perigo mortal. Enquanto isso, o amor representa em sua forma mais tocante a maldição que confina a mulher em seu universo feminino, mulher mutilada, insuficiente em si mesma (BEAUVOIR, 2009, p. 490).

A narrativa, enquanto possibilidade de experimentar o mundo (BENJAMIN, 1994), leva-nos, também, para uma espécie de espelho em que podemos nos enxergar. Bodanzky, ao apresentar Meire, propõe reflexões acerca dos papéis de gênero e do papel da família em nossa sociedade. 0 bom narrador faz isto: dá-nos mais perguntas do que respostas.

E se Beauvoir (2009) afirma que gênero é uma invenção da sociedade, Castells (2000) deixa claro que para quebrar com o ciclo do patriarcado precisamos, então, romper com a instituição da família que é, também, uma construção social. Ou seja, o problema e a solução encontram-se no mesmo lugar.

Narrativas como esta, que tem os dramas pessoais e as questões de nosso tempo como foco do enredo, ajudam-nos a ressignificar debates importantes que, por vezes, foram deixados de lado e normalizados, mas, sem dúvida, há muitas mulheres como Meire que sofrem caladas dentro de casa, e essas histórias precisam ser vistas.

0 feminino presente em Bicho de sete cabeças, representado pela personagem Meire, é frágil, dependente e infeliz. Tem, na figura daquela mulher, as opressões e os silenciamentos que os movimentos feministas tentam há tanto tempo superar. Sempre em desvantagem em relação ao outro, ela é a "mãe de Neto"' ou a "mulher de Wilson", nunca é, simplesmente, ela mesma. Importante reforçar que nem mesmo na filha mais velha, também mulher, Meire encontra algum apoio ou refúgio, já que essa personagem também reproduz os modelos patriarcalistas, fazendo de Wilson, o pai, seu aliado e mentor, sendo ele quem a apoia, competindo pelo afeto e reconhecimento na relação com o irmão.

Meire é vítima de uma sociedade que tem, na figura masculina, seu instrumento de controle e, sobretudo, de domínio. Por meio das desigualdades econômicas, das imposições morais e da supressão de direitos reprodutivos, os homens perpetuam seu poder. Ainda que mude, por ora, muitas mulheres ainda são um tanto Meire, pelo que vale a narrativa de Bicho de sete cabeças como forma não apenas de representar essa realidade que ainda persiste, mas sobretudo por convidar a refletir sobre formas de repensá-la e, aos poucos, transformá-la. 


\title{
The feminine in the film Bicho de sete cabeças by Laís Bodanzky
}

\begin{abstract}
The present article is part of a larger research, which resulted in a master's thesis, in which we sought to understand the representations of contemporary femininity in the works of Brazilian filmmaker Lais Bodanzky. In this way, the investigations were carried out based on the methodologies of narrative analysis, proposed by Cândida Vilares Gancho (2006), and filmic analysis, proposed by Francis Vanoye and Anne Goliot-Lété (2012). In this study, the cut is made from the analysis of the supporting character Meire, from the movie Bicho de sete cabeças (2001). The results point to a representation of a feminine marked by patriarchy and silencing.
\end{abstract}

Keywords: Cinematographic narrative. Feminine. Patriarchalism. Bicho de sete cabeças. Laís Bodanzky.

\section{REFERÊNCIAS}

BATISTA, E. L. A mulher criativa sempre existiu, mas a história apagou, diz Lais Bodanzky. Folha de S.Paulo, São Paulo, 10 jan. 2020. Disponivel em https://www1.folha.uol.com.br/ilustrada/2020/01/a-mulher-criativa-sempre-existiu-mas-a-historia-apagou-diz-lais-bodanzky.shtml?origin=folha. Acesso em: 10 de jun. 2020.

BEAUVOIR, S. de. O segundo sexo. Tradução Sérgio Milliet. 2. ed. Rio de Janeiro: Nova Fronteira, 2009.

BENJAMIN, W. 0 narrador, considerações sobre a obra de Nicolai Leskov. In: BENJAMIN, W. Magia e técnica, arte e política: ensaios sobre literatura e história da cultura. Tradução Sérgio Paulo Rouanet. 7. ed. São Paulo: Brasiliense, 1994. v. 1. p. 197-221. (Obras escolhidas).

BICHO de sete cabeças. [Compositor e intérprete]: Geraldo Azevedo. Direção de Produção: Carlos Alberto Sion. São Paulo: Epic/CBS, 1979. (LP).

BICHO de sete cabeças. Direção: Lais Bodanzky. São Paulo: Buriti Filmes; Gullane; Dezenove Som e Imagens; Fábrica Ci, 2001. 1 DVD (84 min).

CASTELLS, M. O poder da identidade. Tradução Klauss Brandini Gerhardt. 2. ed. São Paulo: Paz e Terra, 2000.

CAVASSANI, M. F. Cinema e mulher: os femininos nas composições das narrativas cinematográficas de Laís Bodanzky. 2020. 150 f. Dissertação (Mestrado em Comunicação e Cultura) Programa de Pós-Graduação em Comunicação e Cultura, Universidade de Sorocaba (Uniso), Sorocaba, 2020.

GANCHO, C. V. Como analisar narrativas. 9. ed. São Paulo: Ática, 2006.

QUEM somos nós? Cinema Brasileiro por Laís Bodanzky. Direção: Coleta Filmes. São Paulo: Casa do Saber; Quem Somos Nós, 9 ago. 2016. 1 vídeo (72 min). Publicado pelo canal Quem 
Somos Nós? Disponivel em: https://www.youtube.com/watch?v=agCDioT3aWI. Acesso em: 10 jun. 2021.

SGANZERLA, C. 0 futuro do cinema. Revista Faap, São Paulo, dez. 2019. Disponivel em: http://revista.faap.br/o-futuro-do-cinema-marina-person-caio-gullane-martha-nowill-laisbodanzky-vestibular/. Acesso em: 10 fev. 2020.

SOBRE nós: Laís Bodanzky. Buriti Filmes, São Paulo, 2021. Disponivel em: http://www.buritifilmes.com.br/a-lais.php?cat=lais. Acesso em: 12 jun. 2021.

VANOYE, F.; GOLIOT-LÉTÉ, A. Ensaio sobre análise fillmica. 7. ed. Campinas: Papirus, 2012. 